\title{
Clinical utility of ingenol mebutate in the management of actinic keratosis: perspectives from clinical practice
}

This article was published in the following Dove Press journal:

Therapeutics and Clinical Risk Management

\author{
Nevena Skroza \\ Nicoletta Bernardini \\ Ilaria Proietti \\ Concetta Potenza \\ Dermatology Unit "Daniele \\ Innocenzi", Department of \\ Medical-Surgical Sciences and \\ Bio-Technologies, Sapienza University \\ of Rome, Fiorini Hospital, Polo \\ Pontino, 040 I 9 Terracina, Italy
}

\begin{abstract}
Actinic keratoses (AKs) are epidermal cutaneous neoplasia observed predominantly in middle-aged and older subjects with mainly photo type I and photo type II on sun-exposed surfaces as a result of DNA damage. AKs have historically been characterized as being "precancerous"; however, now it is considered by many authors a carcinoma in situ that can persist or progress to invasive squamous cell carcinoma (SCC) with metastatic potential. Despite the advances in the recognition of typical clinic, dermoscopic and histologic patterns, currently it is not yet possible to predict which AKs will progress to SCC. For this reason, early diagnosis and effective therapy are recommended based on cost/risk/benefit analysis. Current treatment consists of lesion-directed or field-directed therapies or a combination of both. Among the topical field therapies, ingenol mebutate stands out for its therapeutic efficacy, both as directed lesion therapy and as field directed therapy. The aim of this review is to demonstrate the utility of ingenol mebutate in the management of AK in daily clinical practice and to highlight data from real world in order to confirm evidence from pivotal studies. In order to explore clinical data from real world, PubMed searches were performed with the search terms "clinical data ingenol mebutate" and "real world ingenol mebutate". The hits were examined for relevant articles using defaults criteria. The timeframe for the sample search started from the first publication on this topic in 2008 up to now. A total of 23 articles were found using the keywords specified above. The overview points out a low number of real-life studies on the effectiveness and tolerability of this novel treatment due to short period of clinical experience for its recent approval. Further real-life studies are required in order to better identify the efficacy, safety and adherence of the drug on a larger population.
\end{abstract}

Keywords: ingenol mebutate, actinic keratosis, field cancerization, real world, photodamage, novel treatment

\section{Introduction}

Actinic keratoses (AKs) are common epidermal cutaneous neoplasia that are observed predominantly in middle-aged and older subjects with mainly photo type I and photo type II on sun-exposed surfaces as a result of DNA damage due to cumulative dose of UV radiation absorbed during life. They represent one of the clinical signs of skin photoaging, which is most often characterized by actinic lentigines (sunspots) or wrinkles. ${ }^{1}$ Over the last decades, the incidence of AK has continuously increased. It has an approximate prevalence of $79 \%$ in men and 68\% in women aged between 60 and 69 years. $^{2}$ The prevalence is highest in regions with high UV exposure, especially in Australia, where the prevalence rate among middle-aged adults ( $>40$ years old) ranges from $40 \%$ to $60 \% .^{3}$ Based on recent data of an Italian multicentric study ( 24 general
Correspondence: Nevena Skroza Dermatology Unit "Daniele Innocenzi", Department of Medical-Surgical Sciences and Bio-Technologies, Sapienza University of Rome, A. Fiorini Hospital, Via Firenze, snc, Polo Pontino, 040 I 9 Terracina, Italy Tel +39077370 853I

Fax +39077370 8399

Email nevena.skroza@uniromal.it 
dermatology clinics) conducted between December 2014 and February 2015, AK prevalence in patients aged $\geq 30$ years was $27.4 \% ; 34.3 \%$ in men and $20 \%$ in women. More than half of patients had 1-5 AK lesions, and over three quarters had face or neck lesions. ${ }^{4}$

The major risk factors of developing AKs are photo type I and II, male sex, advanced age, freckles, high lifetime sun exposure, history of pediatric solar erythema and use of some potentially photosensitizing drugs (thiazide diuretics, amiodarone and diltiazem). Furthermore, in patients undergoing immunosuppressive treatments, the risk has increased significantly, as well as the risk of developing invasive and metastatic forms of squamous cell carcinoma (SCC). ${ }^{5}$

Clinically, AK usually presents as erythematous, scaly patch or papule varying in size from a few millimeters to 1-2 cm, covered by slight desquamation or dry and adherent scales on an erythematous base. ${ }^{1,6}$ AKs are usually multiple and are most commonly localized on the face, ears, neck, bald scalp, extensor surface of the extremities and lower lip. There are some clinical variants of AK: hyperkeratotic form, which occurs more frequently as a firm infiltrated papule, covered by a keratotic scale rough on palpation; the pigmented form, similar to a solar lentigo; the skin horn, characterized by hyperkeratotic conic protuberance. Actinic cheilitis is the term used for AKs appearing on the lips, usually formed by the confluence of several AKs involving the lower lip.

AKs are asymptomatic, although some patients report itching, burning or a splinter-like sensation in the affected skin area.

In addition to these visible lesions, there are invisible subclinical AKs that are estimated to occur up to ten times more often than visible AKs. These lesions arise on an area of photo-damaged skin called field cancerization. ${ }^{1}$

Sometimes, clinical aspects are unsatisfactory for correct diagnosis of $\mathrm{AK}$. In these cases of uncertain diagnosis, dermoscopy is a very useful method with high sensitivity and specificity (98.7\% and 95\%, respectively) for the diagnosis of $\mathrm{AK}^{7}$

Histologically, AKs have traditionally been categorized as KIN I or AK I if focal atypia of basal keratinocytes involves only the lower third of the epidermis, KIN II/AK II if atypia affects the lower two thirds of the epidermis or KIN III/AK III if the atypical cells extend also to the upper layers. ${ }^{8}$ The alterations described previously are not limited to skin lesions visible to clinical observation and dermoscopic examination but they occur in photo-damaged skin area known as field cancerization, in which there are genetically altered cells but histologically free of atypia that are flanked by malignant cells. ${ }^{9}$

AKs have historically been considered as "precancerous" or "premalignant" as these lesions are confined to the epidermis without metastatic potential. ${ }^{10}$ Many authors have affirmed that these lesions are pre-cancerous epithelial tumors potentially developing into SCC. ${ }^{11-13}$ Nevertheless, this hypothesis is in contrast to the evidence that $\mathrm{AK}$ shares histopathologic criteria, genetic tumor markers and identical p53 gene mutations with SCC.

The visible clinical lesions are recognized as the initial manifestation of a multi-step carcinogenesis process or disease continuum that can progress from initial subclinical keratinocyte dysplasia into invasive SCC. ${ }^{14}$

Recent studies have showed that AKs with atypical cells present only in the basal layers (classified as AK I) are the most common precursors of invasive squamous cell carcinoma (iSCC) of the skin. Due to the presence of atypia in the basal layer as well as the risk of progression to invasive cancer, $\mathrm{AK}$ is considered now by many authors as a carcinoma in situ that can persist or progress to iSCC.

About the actual risk for an individual AK development to invasive SCC, several studies ${ }^{14,15}$ have highlighted that approximately $8 \%$ of all AKs progress into invasive SCCs. Other data report that in a patient with ten AKs, the risk of malignant progression is $9.6 \%$, while in a patient with seven to eight $\mathrm{AKs}$, the risk is $6 \%-10 \%$ over a 10 -year period. ${ }^{16}$

The risk of AK evolving into SCC is increased in males and individuals with photo type I and II, a family history of skin cancer and a human papillomavirus infection or in immune-suppressed individuals (being at a risk increased by 250$){ }^{6}$

Despite the advances in the recognition of typical clinical, dermoscopic and histologic patterns, currently it is not yet possible to predict which AK will progress to SCC. ${ }^{17}$

For this reason, prevention, early diagnosis and effective treatment are recommended based on cost/risk/benefit analysis.

Current treatment consists of a multitude of lesiondirected or field-directed therapies or a combination of both. The therapy choice is influenced by several factors, such as number of lesions, natural history of lesions, localization and extension of the disease, patient's age, comorbidity and immunosuppression, personal history of previous skin lesions, previous treatments of AKs and personal preferences of the patient and physician. Lesion-directed treatment is usually a first-line approach for isolated lesions, while a fielddirected approach is used when multiple lesions are present. ${ }^{6}$ The goals of field therapy are to remove clinically visible as 
well as subclinical lesions and to prevent the development of invasive SCC. Patients with multiple lesions (lesion field) or with a history of multiple lesions should benefit from a topical treatment with diclofenac 3\% gel, ingenol mebutate gel, imiquimod cream, photodynamic therapy with aminolevulinic acid or methyl aminolevulinate or 5-fluorouracil 5\% cream. ${ }^{17}$ The aim of this review is to demonstrate the utility of ingenol mebutate in the management of AK in daily clinical practice and to point out data from the real world in order to confirm evidence from pivotal studies.

\section{Review of literature}

\section{Pharmacology, mode of action, pharmacokinetics, dosing and administration of ingenol mebutate}

Ingenol mebutate (ingenol-3-angelate, previously PEP005) is a novel topical chemotherapy field-directed therapy for AK, which was approved by the Food and Drug Administration in January $2012 .{ }^{18}$ It is a hydrophobic, macrocyclic diterpene ester extracted from an active fraction of the sap of a non-invasive weed Euphorbia peplus, ${ }^{19}$ a plant that has traditionally been used as a home treatment for various skin diseases, including AK and basal cell carcinomas. ${ }^{20}$

The therapeutic effect of ingenol mebutate has been partially explained with a dual mechanism of action; it induces rapid (1-2 hours after application) cell death in transformed keratinocytes through disruption of plasma membrane and subsequent mitochondrial swelling and, within days, stimulates neutrophil-mediated form of antibody-dependent cytotoxicity that eliminates residual tumor cells. ${ }^{21}$

Ingenol mebutate is an agonist of intracellular protein kinase $\mathrm{C}$ (PKC), which is involved in the signaling pathways of different physiologic functions, such as cell proliferation, differentiation and senescence, cell survival/death, invasion and angiogenesis. ${ }^{22}$ The activation of the pro-apoptotic intracellular PKC induces apoptosis of dysplastic keratinocytes, whereas keratinocytes with normal differentiation are resistant to the PKC mediated pro-apoptotic effects. ${ }^{23}$ The activation of PKC/MEK/ERK pathway results also in immunostimulatory effects with an infiltration of neutrophils into the area of application and antibody production that stimulates cytotoxic $\mathrm{T}$ cells against dysplastic cells. ${ }^{24}$

Ingenol mebutate is a substrate for P-glycoprotein. After topical application, it passes the stratum corneum barrier through P-glycoprotein absorptive drug transport and exerts its action in the dermis and hypodermis where it causes vascular damage. ${ }^{19,25}$ The systemic absorption from the skin is minimal. ${ }^{26}$ Ingenol mebutate and its metabolites have been shown to have no effect on the cytochrome P450 (CYP) enzyme system. ${ }^{27}$

Ingenol mebutate, formulated as a propyl alcohol-based gel for topical use, ${ }^{28}$ is available in two different concentrations. The $0.015 \%$ gel formulation is divided into three monodoses for three consecutive days of application on the face and scalp, whereas the $0.05 \%$ gel formulation is divided into two monodoses for two-day treatment of the trunk or extremities. $^{23,29}$ Every monodose is sufficient to treat a field area of $25 \mathrm{~cm}^{2}$.

\section{Quality of life, patient satisfaction and adherence to treatment}

Generally, the therapy is well tolerated. Due to its mechanism of action, the most common adverse events are the application-site conditions such as erythema, pruritus, flaking/scaling/dryness, erosions and scabbing/crusting. ${ }^{30}$ These local skin responses are dose related and tend to spontaneous resolution within one month after treatment without sequelae. ${ }^{19}$ The severity of these adverse reactions is correlated with the initial damage within the affected skin field. ${ }^{31}$ (Figures 1 and 2).

Results of Phase II and Phase III studies have demonstrated that ingenol mebutate gel was effective and well
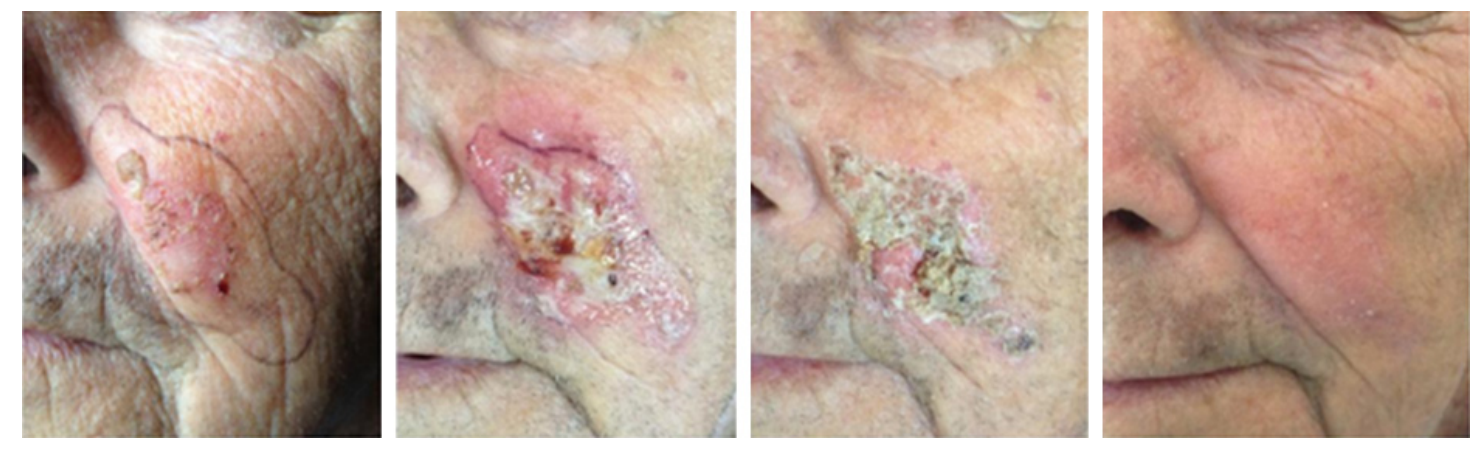

Figure I Clinical aspects at baseline, during and after ingenol mebutate treatment in a 65-year-old man. 

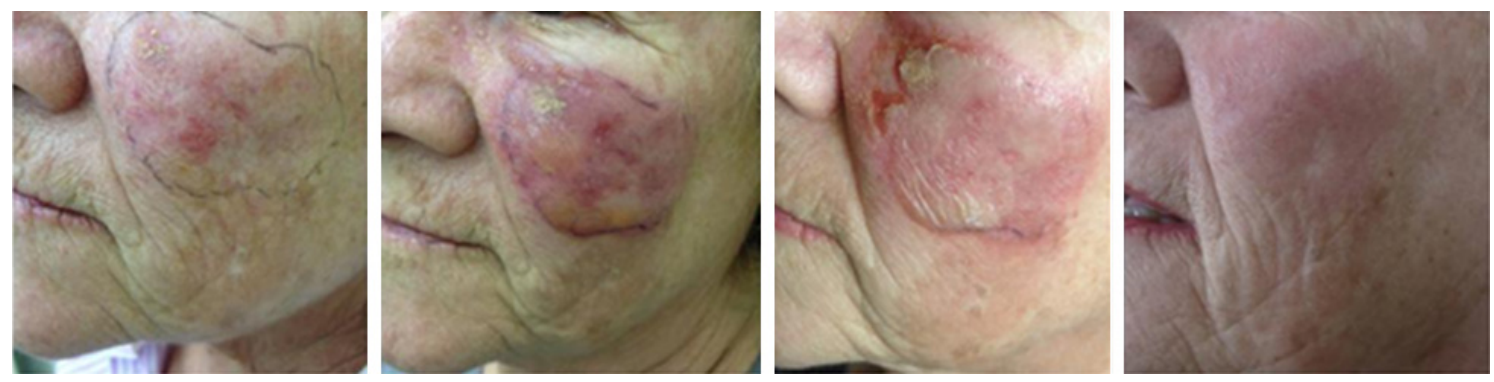

Figure 2 Clinical aspects at baseline, during and after ingenol mebutate treatment in a 7I-year-old woman.

tolerated by patients, with reduction until disappearance of clinically visible AKs and resolution of lesion over one year. ${ }^{24,32,33}$ Greater improvements were reported in face/scalp compared with trunk/extremities. ${ }^{34}$

In 2015, Jubert-Esteve et al conducted a pilot study in Spain to evaluate quality of life (QoL) and side effects in patients affected by AKs receiving treatment with ingenol mebutate. This study observed that QoL improved after treatment and that it depended on a subjective patient scale. Moreover, side effects affected neither QoL nor patients' satisfaction with treatment, maybe because of their short duration and easiness of application..$^{35}$

Evidence from randomized controlled trial (RCT) showed extremely high adherence rates (over 95\%) in patients receiving ingenol, as well as improvement of patients' QoL..$^{33,35}$ Recently, Ricci et al showed real-life efficacy and safety of ingenol mebutate, demonstrating that the majority of patients $(82 \%)$ considered the treatment more convenient compared to other therapeutic options. ${ }^{36}$

\section{Clinical data from real world}

In order to explore clinical data from real world about this novel treatment for AKs, PubMed searches were performed with the search terms "clinical data ingenol mebutate" and "real world ingenol mebutate". The hits were examined for relevant articles using defaults criteria. The timeframe for the sample search started from the first publication on this topic in 2008 up to March 2018. Articles were classed as relevant if ingenol mebutate was studied to treat AK in real world, and an effect was reported with sex/site/AK number or grade/previous treatment differences.

A total of 23 articles were found using the abovementioned keywords. Two of them were excluded from these reviews as they do not treat skin carcinomas but colon cancer cells, ${ }^{37}$ or expression of human hepatic drug transporter. ${ }^{38}$

One study has not been considered because it describes only the mechanism of action of the drug without clinical evidence. ${ }^{39}$ Furthermore, all trial-based articles were excluded. ${ }^{40-46}$

Two other articles have the aim to develop therapeutic algorithms for AK that can be used in everyday clinical practice in a real-world context, but they are also based on clinical trials. In the first article, an international panel of 14 experts on AK proposed a therapeutic approach to AK that can be used in real-life setting starting from data derived from clinical trials and authors' practical clinical experience. The authors specify that in 2017 there was not enough published information related to the real-life practice and therefore recommendations are based on consensus of their practical clinical experience. ${ }^{47}$

In the second work, Drèno et al proposed AK treatment algorithm for daily practice in France but they evaluated ingenol mebutate's efficacy through pooled analysis of previous trials. ${ }^{48}$

Most recent paper regarding real-world data on ingenol mebutate has been written by Norrlid et al. Real-world Swedish and Danish patients have been studied to obtain patient-reported outcomes in topical field treatment. The results show higher patient satisfaction with ingenol mebutate treatment compared with diclofenac $(P=0.006)$ and a higher treatment adherence for ingenol mebutate compared to both diclofenac $(P<0.001)$ and imiquimod $(P=0.007)$, most likely due to a reduced treatment duration. Local skin reactions (LSRs) were less common in patients treated with diclofenac compared to imiquimod group $(P<0.001)$ or ingenol mebutate group $(P<0.001)$ and less common with imiquimod group compared to ingenol mebutate group $(P=0.015)$. A limitation of this study is that the data are only based on patient's self perception, lacking in clinician's objective evaluation. ${ }^{49}$

The most interesting paper on efficacy and safety in reallife use of ingenol mebutate for the treatment of AK was published by Ricci et al. They enrolled 88 patients during the study period (April 2014-April 2015) with multiple AKs of 
the face and scalp. Real-life lesion clearance rate of AKs on the scalp was found to be higher in this study compared to previous $\mathrm{RCTs}^{33}$ (80\% vs 53\%) and clearance rate for AKs located on the face was similar to previous RCT reports ${ }^{33}$ ( $82 \%$ vs $78 \%$ ). AK on the scalp was higher in the study compared to previous RCTs ${ }^{33}$ ( $80 \%$ vs $53 \%$ ). At one-week follow-up, patients with photo type I-II showed stronger local site reactions, like erythema and skin erosions than patients with higher photo type. Furthermore, patients with residual local site reaction at eighth week of follow-up would seem to show reduced clinical outcomes. Real clinical significance should be better evaluated. Authors point out the differences in the number of lesions for field in RCTs compared to reallife studies (4-8 vs $>9$ lesions) and the difficulty of correct evaluation of patient adherence to therapy in the context of an RCT. ${ }^{36}$

In 2016, a retrospective cohort study was performed in order to evaluate factors influencing response to ingenol mebutate therapy for AK of the face and scalp. In total, 130 patients were enrolled and efficacy was evaluated comparing clinical and dermoscopic features collected at baseline and at each control visit (days 2, 3, 8, 15, 29 and 57). All the patients completed the three applications of ingenol mebutate $0.015 \%$ gel; 101 subjects $(77.7 \%)$ underwent face treatment and 29 (22.3\%) underwent scalp treatment. Regarding efficacy, the great majority of study population $(119,91.5 \%)$ reached at least a $75 \%$ clearance of AKs, in particular 58 patients (44.6\%) achieved a complete response and $61(46.9 \%)$ a partial one; poor responders were $11(8.5 \%)$. LSRs were evaluated at each control visit. Ingenol mebutate $0.015 \%$ gel was found to be independently related to both the head site and the level of LSR, demonstrating a higher efficacy on AKs localized on the face and in those with more severe LSRs. Considering reported data, ingenol mebutate treatment seems to be more effective on the face than on the scalp and the efficacy seems to be directly related to the level of LSR. ${ }^{50}$

Sometimes real-word use of ingenol mebutate is not limited to the treatment of classically defined AK. Grandi et al described a single-center experience in the treatment of "hydroxyurea-induced squamous dysplasia" (HISD) with ingenol mebutate. ${ }^{51}$ Hydroxyurea is an antimetabolite drug used in the treatment of chronic myelogenous leukemia, polycythemia rubra vera, myeloproliferative disorders and sickle cell anemia. In 2004, Sanchez-Palacios and Guitart used the term "hydroxyurea-induced squamous dysplasia" to identify a drug-induced non-melanoma skin cancer (NMSC) with a synergistic carcinogenic action between chronic sun exposure and drugs. This statement justifies the use of the same therapies for both NMSC and drug-induced NMSC. ${ }^{52}$ Five patients with HISD on the face or scalp or trunk or extremities were treated with a cycle of ingenol mebutate at both concentrations $(150 \mu \mathrm{g} / \mathrm{g}$ or $500 \mu \mathrm{g} / \mathrm{g})$ depending on lesion localization. At 57 days of follow-up, the authors reported an overall response rate of $87.5 \%$, a reduction of $78.0 \%$ of total lesions compared to time $0(P<0.01)$, in absence of severe adverse event (grade $3-4) .{ }^{51}$

At last, Athanasakis et al performed a cost-effectiveness analysis of ingenol mebutate (IM) versus other topical alternatives for the treatment of $\mathrm{AK}$ in Greece, concluding that IM could be the most cost-effective first-line topical field treatment option. ${ }^{53}$

\section{Conclusion}

Over the last decades, the incidence of AK has continuously increased. ${ }^{6}$ Although previously AKs were considered as precancerous lesions, to date greater evidence consider it as a carcinoma in situ that can persist or progress to iSCC with metastatic potential. Furthermore, in addition to these visible lesions, there are invisible subclinical AKs that are estimated to occur up to 10 times more often than visible AKs. These lesions arise to a large extent in photo-damaged skin area called field cancerization. ${ }^{1}$ To date, there are no defined and reliable clinical predictors that identify an AK that could be transformed into iSCC. This recent evidence demands an early diagnosis and an effective treatment based on cost/ risk/benefit analysis. ${ }^{1,17}$

Current treatment consists of a multitude of lesiondirected or field-directed therapies or a combination of both. In patients with multiple lesions (lesion field) or with a history of multiple lesions, field therapy is preferred. ${ }^{6}$ The goals of field therapy are to remove clinically visible as well as subclinical lesions and to prevent the development of iSCC. Among the topical field therapies, ingenol mebutate, a novel topical chemotherapy, stands out for its short treatment course and efficacy, both as directed lesion therapy and field directed therapy. After topical application, it passes the stratum corneum barrier and exerts its action in the dermis and hypodermis with a minimal systemic absorption, which is effective and well tolerated by patients. ${ }^{33}$

The overview points out a low number of real-life studies on the effectiveness and tolerability of ingenol mebutate due to its recent approval and consequently short period of clinical experience. Real-life studies are essential to translate the RCT results to clinical practice; therefore, further real-life studies are required to better identify the efficacy, safety and adherence of the drug in a larger population. 


\section{Acknowledgments}

Contributors who participated in writing assistance and manuscript preparation: Anzalone Alessia MD, Balduzzi Veronica MD, Colapietra Daniela MD, Mambrin Alessandra MD, Marchesiello Anna MD, Michelini Simone MD, Ersilia Tolino MD who are all from the Dermatology Unit "Daniele Innocenzi", Department of Medical-Surgical Sciences and Bio-Technologies, Sapienza University of Rome, Fiorini Hospital, Polo Pontino, 04019 Terracina, Italy.

\section{Disclosure}

The authors report no conflicts of interest in this work.

\section{References}

1. Filosa A, Filosa G. Actinic keratosis and squamous cell carcinoma: clinical and pathological features. G Ital Dermatol Venereol. 2015; 150(4):379-384.

2. Lai V, Cranwell W, Sinclair R. Epidemiology of skin cancer in the mature patient. Clin Dermatol. 2018;36(2):167-176. Epub 2017 Oct 13.

3. Perera E, Gnaneswaran N, Staines C, Win AK, Sinclair R. Incidence and prevalence of non-melanoma skin cancer in Australia: A systematic review. Australas J Dermatol. 2015;56(4):258-267. Epub 2015 Feb 25.

4. Fargnoli MC, Altomare G, Benati E, et al. Prevalence and risk factors of actinic keratosis in patients attending Italian dermatology clinics. Eur J Dermatol. 2017;27(6):599-608.

5. Green AC. Epidemiology of actinic keratoses. Curr Probl Dermatol. 2015;46:1-7.

6. Arenberger P, Arenbergerova M. New and current preventive treatment options in actinic keratosis. J Eur Acad Dermatol Venereol. 2017; 31(Suppl 5):13-17.

7. Warszawik-Hendzel O, Olszewska M, Maj M, Rakowska A, Czuwara J, Rudnicka L. Non-invasive diagnostic techniques in the diagnosis of squamous cell carcinoma. J Dermatol Case Rep. 2015;9(4):89-97.

8. Fernandez Figueras MT. From actinic keratosis to squamous cell carcinoma: pathophysiology revisited. J Eur Acad Dermatol Venereol. 2017;31(Suppl 2):5-7.

9. Jetter N, Chandan N, Wang S, Tsoukas M. Field Cancerization Therapies for Management of Actinic Keratosis: A Narrative Review. Am J Clin Dermatol. 2018;19(4):543-557.

10. Conforti C, Beninanti E, Dianzani C. Are actinic keratoses really squamous cell cancer? How do we know if they would become malignant? Clin Dermatol. 2018;36(3):430-432.

11. Jorizzo JL, Carney PS, Ko WY, et al. Treatment options in the management of actinic keratosis. Cutis. 2004;74(Supp16):9-17.

12. Jerry KL, Tan D, Thomas R, Poulin Y, Maddin F, Tan J. Efficacy of Imiquimod as an Adjunct to Cryotherapy for Actinic Keratoses. J Cutan Med Surg. 2007;11(6):195-201

13. Ratushny V, Gober MD, Hick R, Ridky TW, Seykora JT. From keratinocyte to cancer: the pathogenesis and modeling of cutaneous squamous cell carcinoma. J Clin Invest. 2012;122(2):464-472.

14. Siegel JA, Korgavkar K, Weinstock MA. Current perspective on actinic keratosis: a review. Br J Dermatol. 2017;177(2):350-358.

15. Werner RN, Sammain A, Erdmann R, et al. The natural history of actinic keratosis: a systematic review. Br J Dermatol. 2013;169:502-518.

16. Ko CJ, Cj K. Actinic keratosis: facts and controversies. Clin Dermatol. 2010;28(3):249-253.

17. Chetty P, Choi F, Mitchell T. Primary care review of actinic keratosis and its therapeutic options: a global perspective. Dermatol Ther. 2015; 5(1):19-35.

18. Ali FR, Wlodek C, Lear JT. The role of ingenol mebutate in the treatment of actinic keratoses. Dermatol Ther. 2012;2(1):8.
19. Aditya S, Gupta S. Ingenol mebutate: A novel topical drug for actinic keratosis. Indian Dermatol Online J. 2013;4(3):246-249.

20. Green AC, Beardmore GL. Home treatment of skin cancer and solar keratoses. Australas J Dermatol. 1988;29(3):127-130.

21. Bobyr I, Campanati A, Consales V, Giuliodori K, Scalise A, Offidani A, Efficacy OA. Efficacy, safety and tolerability of field treatment of actinic keratosis with ingenol mebutate $0.015 \%$ gel: a single center case series. Springerplus. 2016;5:627.

22. Gupta AK, Paquet M. Ingenol Mebutate: A Promising Treatment for Actinic Kératoses and Non melanoma Skin Cancers. J Cutan Med Surg. 2013;17(3):173-179.

23. Alchin DR. Ingenol mebutate: a succinct review of a succinct therapy. Dermatol Ther. 2014;4(2):157-164.

24. Martin G, Swanson N. Clinical findings using ingenol mebutate gel to treat actinic keratoses. J Am Acad Dermatol. 2013;68(1 Suppl 1): S39-S48

25. Li L, Shukla S, Lee A, et al. The skin cancer chemotherapeutic agent ingenol-3-angelate (PEP005) is a substrate for the epidermal multidrug transporter (ABCB1) and targets tumor vasculature. Cancer Res. 2010;70(11):4509-4519.

26. Rosen RH, Gupta AK, Tyring SK. Dual mechanism of action of ingenol mebutate gel for topical treatment of actinic keratoses: rapid lesion necrosis followed by lesion-specific immune response. $J$ Am Acad Dermatol. 2012;66(3):486-493

27. Fidler B, Goldberg T. Ingenol mebutate gel (Picato): a novel agent for the treatment of actinic keratoses. P T. 2014;39(1):40-46.

28. Fallen RS, Gooderham M. Ingenol mebutate: an introduction. Skin Therapy Lett. 2012;17:1-3.

29. Ortega del Olmo R, Salido-Vallejo R. Ingenol mebutate for the treatment of actinic keratosis: effectiveness and safety in 246 patients treated in real-life clinical practice. J Dermatolog Treat. 2018;29(4):1.

30. Keating GM. Ingenol mebutate gel $0.015 \%$ and $0.05 \%$ : in actinic keratosis. Drugs. 2012;72(18):2397-2405.

31. Jim On SC, Knudsen KM, Skov T, et al. Relationship between severity of the local skin reactions and the rate of local skin reaction resolution in patients treated with ingenol mebutate gel. Clin Cosmet Investig Dermatol. 2016;9:211-216.

32. Anderson L, Schmieder GJ, Werschler WP, et al. Randomized, doubleblind, double-dummy, vehicle-controlled study of ingenol mebutate gel $0.025 \%$ and $0.05 \%$ for actinic keratosis. J Am Acad Dermatol. 2009; 60(6):934-943.

33. Lebwohl M, Swanson N, Anderson LL, Melgaard A, Xu Z, Berman B. Ingenol mebutate gel for actinic keratosis. N Engl J Med. 2012;366(11): 1010-1019.

34. Augustin M, Tu JH, Knudsen KM, Erntoft S, Larsson T, Hanke CW. Ingenol mebutate gel for actinic keratosis: The link between quality life, treatment satisfication, and clinical outcomes. J Am Acad Dermatol. 2015;72(5):816-821.

35. Jubert-Esteve E, del Pozo-Hernando LJ, Izquierdo-Herce N, BauzáAlonso A, Martín-Santiago A, Jones-Caballero M. Quality of life and side effects in patients with actinic keratosis treated with ingenol mebutate: a pilot study. Actas Dermosifiliogr. 2015;106(8):644-650.

36. Ricci F, Tambone S, Neri L, et al. Real-life efficacy and safety of ingenol mebutate for the treatment of actinic keratosis of the face and scalp: A single arm retrospective study. J Dermatolog Treat. 2016;27(6):525-530.

37. Benhadji KA, Serova M, Ghoul A, et al. Antiproliferative activity of PEP005, a novel ingenol angelate that modulates PKC functions, alone and in combination with cytotoxic agents in human colon cancer cells. Br J Cancer. 2008;99(11):1808-1815.

38. Mayati A, Le Vee M, Moreau A, et al. Protein kinase C-dependent regulation of human hepatic drug transporter expression. Biochem Pharmacol. 2015;98(4):703-717.

39. Stahihut M, Bertelsen M, Hoyer-Hansen M, et al. Ingenol mebutate: induced cell death patterns in normal and cancer epithelial cells. J Drugs Dermatol. 2010;11(10):1181-1192.

40. Vegter S, Tolley K. A network meta-analysis of the relative efficacy of treatments for actinic keratosis of the face or scalp in Europe. PLoS One. 2014;9(6):e96829. 
41. Augustin M, Jh T, Knudsen KM, et al. Ingenol mebutate gel for actinic keratosis: The link between quality of life, treatment satisfaction, and clinical outcomes. J Am Acad Dermatol. 2015;72(5):816-821.

42. Pellacani G, Peris K, Guillen C, et al. A randomized trial comparing simultaneous vs. sequential field treatment of actinic keratosis with ingenol mebutate on two separate areas of the head and body. $J$ Eur Acad Dermatol Venereol. 2015;29(11):2192-2198.

43. Nisticò S, Torchia V, Gliozzi M, Bottoni U, del Duca E, Muscoli C. Pharmacoeconomy of drugs used in the treatment of actinic keratoses. Int J Immunopathol Pharmacol. 2016;29(4):796-804.

44. Anderson L, Jarratt M, Schmieder G, Shumack S, Katsamas WP. Tolerability and pharmacokinetics of ingenol mebutate $0.05 \%$ gel applied to treatment areas up to $100 \mathrm{~cm}^{2}$ on the forearm(s) of patients with actinc keratosis. Clinical Aesthetic Dermatology. 2014;7(12):19-29.

45. Berman B. Safety and tolerability of ingenol mebutate in the treatment of actinic keratosis. Expert Opin Drug Saf. 2015;14(12):1969-1978.

46. Kostovic K, Gulin SJ, Mokos ZB, Ceovic R. Topical Ingenol Mebutate: A New Treatment Modality for Multiple Actinic Keratoses and Field Cancerization. Anticancer Agents Med Chem. 2017;17(10):1-8.

47. Dirschka T, Gupta G, Micali G, et al. Real-world approach to actinic keratosis management: practical treatment algorithm for office-based dermatology. J Dermatolog Treat. 2017;28(5):431-442.
48. Dréno B, Amici JM, Basset-Seguin N, et al. Management of actinic keratosis: a practical report and treatment algorithm from AKTeam ${ }^{\mathrm{TM}}$ expert clinicians. J Eur Acad Dermatol Venereol. 2014;28(9):1141-1149.

49. Norrlid H, Norlin JM, Holmstrup H, et al. Patient-reported outcomes in topical field treatment of actinic keratosis in Swedish and Danish patients. J Dermatolog Treat. 2018;29(1):68-73.

50. Skroza N, Proietti I, Bernardini N, et al. Factors influencing response to ingenol mebutate therapy for actinic keratosis of face and scalp. World J Clin Oncol. 2017;8(5):405-411.

51. Grandi V, Delfino C, Pimpinelli N. Ingenol mebutate in the treatment of 'Hydroxyurea-induced Squamous Dysplasia': a single centre experience. J Eur Acad Dermatol Venereol. 2016;30(7):1129-1132.

52. Sanchez-Palacios C, Guitart J. Hydroxyurea-associated squamous dysplasia. J Am Acad Dermatol. 2004;51(2):293-300.

53. Athanasakis K, Boubouchairopoulou N, Tarantilis F, Tsiantou V, Kontodimas S, Kyriopoulos J. Cost-effectiveness of Ingenol Mebutate Gel for the Treatment of Actinic Keratosis in Greece. Clin Ther. 2017; 39(5):993-1002.
Therapeutics and Clinical Risk Management

\section{Publish your work in this journal}

Therapeutics and Clinical Risk Management is an international, peerreviewed journal of clinical therapeutics and risk management, focusing on concise rapid reporting of clinical studies in all therapeutic areas, outcomes, safety, and programs for the effective, safe, and sustained use of medicines. This journal is indexed on PubMed Central, CAS,

\section{Dovepress}

EMBase, Scopus and the Elsevier Bibliographic databases. The manuscript management system is completely online and includes a very quick and fair peer-review system, which is all easy to use. Visit http://www.dovepress.com/testimonials.php to read real quotes from published authors.

Submit your manuscript here: http://www.dovepress.com/therapeutics-and-clinical-risk-management-journal 